\title{
THE EFFECTS OF THE EMOTION HAPPY AS INDUCED BY COLORS ON THE PERFORMANCE OF GRADE 1 PUPILS IN ADDITION
}

\author{
Michael M Nael \\ Philippine Normal University, Philippines \\ mike_nael@yahoo.com \\ DOI: https://doi.org/10.37134/saecj.vol8.no2.1.2019
}

Received: 05 July 2019; Accepted: 30 October 2019; Published: 20 November 2019

\begin{abstract}
The aim of this study is to determine the effect of the emotion "happy" as induced by colors on the addition performance of grade 1 pupils. The experiment involved the pupils in the experimental group $(n=80)$ were taught addition, using modules developed by the researcher which utilized seductive augmentation of learning materials through colors, the pupils in the control group $(n=70)$ were taught addition using the method in the current math education program which do not utilize emotion-based teaching aids. The study was implemented for 1 week. Pretest and post-test developed by the researcher based on the math competencies for grade 1 of the Department of Education (DepEd) were administered to the pupils before and after the study and data obtained were statistically analyzed. The study found that Gold, Yellow, Rose, Red and Green were respectively the top five colors that induced happy emotion. Although significant statistical difference was registered between the pre-test and post-tests of the control group $(t(70)=-7.04, m=-1.04, s d=1.23, p=<.001)$, the performance of the experimental group registered statistically significant difference over the control group $(t(80)=-26.75, m=-.292, s d=.99, p=<.001$. This showed that the experimental group had better performance than the control group. Thus, there is statistical basis to claim that the emotion happy as induced by certain colors improved the addition performance of grade 1 pupils.
\end{abstract}

Keywords: happy, colors, addition performance, seductive augmentation

\section{INTRODUCTION}

There seems to be consensus among recent researches that emotions do influence learning (e.g., Pekrun \& Linnenbrink-Garcia, 2014). Emotion is related to learning since the emotional brain, the limbic system, opens or closes access to learning, memory and the ability to make novel connections (Vail, 2016). Moreover, to benefit from emotions, teachers ought not to treat them as only the product of the processing of information by the brain, but as something that also directly influence the processes of learning and memory in the brain (Tendler and Wagner, 2015). For it was found that when teachers are conscious of students' emotional state, their attitude and feedback become more effective and timely (Arguedas, Daradoumis, \& Xhafa, 2016). Furthermore, the use of emotion inducers like colors may prove to be the answer in utilizing emotion to improve pupils' performance since well-designed materials were found to induce positive emotions and to facilitate comprehension through warm colors (Plass, Heidig, Hayward, Homer, \& Um, 2014). 


\section{Emotion affects learning}

Learning is an inherently emotional experience where an individual is exposed to many emotions before, during and after the lessons. The learner is frequently exposed to emotions associated with success, failure and challenges from a psychological perspective. Emotions influence the cognitive processes and learning as found by the studies of Izard, (2009); Pekrun (2006) and Russell, (2003) while newer studies established further that emotions influence learning and memory processes which may be useful for the design of effective educational curricula to provide a conducive learning environment for both traditional "live" learning in classrooms and "virtual" learning through online-based educational technologies (Tyng, Amin, Saad, \& Malik, 2017). Aside from this, it was found that when students were made aware of their emotions and guided by specific teaching strategies, their learning performance improves in relation to their motivation, engagement and self-regulation. Likewise, when teachers are conscious of students' emotional state their attitude and feedback become more effective and timely (Arguedas et al., 2016). In contrast, individuals having greater difficulties in emotion regulation showed poor performance in academics. Thus, the need for psychologists and teachers to devise some intervention plan specifically related to difficulties in emotion regulation in order to assist students to improve their learning and performance (Singh \& Singh, 2013). This is because emotions constitute potent, pervasive, predictable, sometimes harmful and sometimes beneficial drivers of decision making (Lerner, Li, Valdesolo, \& Kassam, 2015) and had a larger impact on learners' intrinsic motivation, including the motivation to continue working with the material (Heidig, Müller, \& Reichelt, 2015). Lastly, emotions affect learning since emotions serve as filters anticipating threats to the self-image protecting self-esteem was posited by Wolfe (2006). He averred that the freedom to learn is heavily dependent on emotions experienced while learning, which educators can have some control. Students learn new knowledge better if there is trust toward the person offering new knowledge or if they believe that the current experiences will not be harmful to them.

\section{Colors Induce the Positive Emotion Happy that Affects Learning}

Recent studies posited that different colors can have different functions in human memory. Through seductive augmentations, colors may be used in the teaching and learning of basic math skills. Seductive augmentation uses interesting colors, visuals illustrations that contain highly interesting, but unimportant information, to promote or help understanding the topic and is used as strategy to engage a learner's attention and promote interest (Schraw \& Lehman, 2001).

Studies found that warm colors facilitates Comprehension (Plass, Heidig, Hayward, Homer, \& Um, 2014). Red was most commonly associated with negative emotion and emotionladen words, whereas green was found to strongly increased memory for positive words while yellow and white were associated with positive emotion and emotion-laden words, respectively (Sutton \& Altarriba, 2015). Blue was found to increase relaxation and calm feelings of participants compared to the other colors.(Al-Ayash, Kane, Smith, \& Green-Armytage, 2016). These effects were not only determined by the hue of a color as was often assumed, but by all the three color dimensions as well as their interactions (Wilms \& Oberfeld, 2017). All three attributes of colors, i.e. hue, Chroma, and Lightness, influenced the emotional responses, and especially, chroma was always positively correlated with each of the three emotional dimensions. Moreover, emotional responses to color vary more strongly with regard to tone than to hue categories (Suk \& Irtel, 2010). 
The emotional design hypothesis postulates that designing features with the goal to impact learners' emotions will influence learning performance (Park, Kn€orzer, Plass, \&Brünken, 2015) and if elements will appear as visually appealing, cognitive processes are enhanced and lead to better learning scores (Mayer \& Estrella, 2014; Plass, Homer, \& Hayward, 2009). Moreover, round face-like shapes, independently as well as together with warm colors facilitated comprehension while round face-like shapes when used with neutral colors facilitated transfer (Plass et al., 2013).

But the mathematical achievements of Filipino students were very low as shown by the achievement rate of grade VI students in Mathematics at the National Achievement Test (NAT) from 2008 to 2012 that ranges from $63.26 \%$ to $68.43 \%$ and which saw a decline in the year 2013 to $66.32 \%$ (Department of Education, 2015). The modern theories and pedagogies introduced in the K-12 program which focused on cognitive strategies may not be enough. The mounting evidences found in the studies in other countries on the beneficial effects of emotions in learning may hold the key to the effective and efficient learning of mathematical skills and to the improvements in the performance of Filipino pupils. The use of induced happy emotions through colors may be a better alternative to the current focus on rational practices that demotes the role of emotions in learning and may be more suited in the Philippine setting since Filipinos are generally perceived to be music lovers, cheerful and emotional rather than rational in their dispositions (Jocano, 2000).

Thus, the overarching objective of this research was to develop emotion-based teaching aids aimed to improve the performance in addition and subtraction of grade 1 pupils through happy emotion induced by colors. From the overarching objective, this study set out to pursue the following specific objectives:

1. To identify colors that induce happy emotion;

2. To develop emotion-based teaching aids utilizing these colors to induce happy emotions aimed at improving the performance in addition and subtraction of grade 1 Filipino pupils; and

3. To determine if the pupils who were taught using the emotion-based teaching aids that induced happy emotion through colors performed better than those who did not use the emotion-based teaching aids.

In order to achieve the overarching objectives and its three specific objectives, answers to the following questions were sought:

Research Question 1: Is there any color that induces happy emotion?

Research Question 2: Were the performance in Addition of the experimental group better than the control group?

The following hypotheses were tested in this study:

Ho 1: There is no statistically significant difference in the antecedent and the consequent emotions induced by colors.

Ho 2: There is no statistically significant difference in the performance in addition of the control and the experimental groups 


\section{Research Design}

This research conducted surveys, developed teaching aids and conducted an experiment using emotion-based teaching aids that consisted of five lessons in addition. The survey and the experiment were conducted for five days in two schools in Manila, Philippines

The pretest-posttest design was employed in this study to determine if the intervention had caused better performance in the participants. Since the pupils were subjected to the same lessons with different treatments any significant differences in the performance of the two groups were likely from the intervention (Blair, Czaja \& Blair, 2013). The validity and reliability of the instruments and the teaching aids were insured by attempting to have high face validity, concurrent validity and predictive validity through the employment of a single-blind study where the participant does not know the condition, they are in. This method ensured there was little demand characteristics, such as trying to behave a certain way because they think that is what is expected of them. The Cronbach's alpha method was used in order to determine the reliability of the instruments and the learning aids. The teaching aids and instruments were also subjected to expert validation, pilot testing using different groups and by comparing the results to find out if the teaching aids and the instruments can generate consistent results.

The teaching aids developed by the researcher were evaluated by twenty-five teachers of grade 1 pupils from different schools in Manila and pilot tested to sixty grade 1 pupils from Fernando Ma. Guerrero Elementary school in Manila. Thirty pupils were randomly drawn from a class assigned as the control group and thirty pupils were randomly drawn from a class assigned to the experimental group. These two classes involved in the pilot testing were not part of the survey and the experiment.

The survey involved two hundred grade 1 pupils $(N=200)$ whose classes were randomly selected from the grade 1 classes of Fernando Ma. Guerrero Elementary School. The pupils involved 97 male (48.50\%) and 103 females (51.50\%).

The development of Emotion based Learning Modules to improve the performance in addition of grade 1 pupils, involved two phases. Phase 1 developed a tool in identifying what colors induced best the positive emotion happy. Through several refinements of items, the color inducing emotion questionnaire (CIEQ) was conceived, providing a suitable tool for identifying which colors best induced the positive emotion happy. Phase 2 developed the Emotion Based Learning Modules (EBLM)in addition and subtraction together with the pre-test and post-test to measure the effects of emotion based learning on the performance of grade 1 pupils. Phase 3 validated and pilot tested the modules.

\section{Stage 1: Development of Color Inducing Emotion Questionnaire (CIEQ)}

The Color Induced Emotion Questionnaire (CIEQ) was develop using twelve colors. To maintain validity and sensitivity this tool was designed to exclusively induced emotion through the subjective experiences of respondents. The CIEQ provides a tool for establishing specific color that induced the positive emotion of happy. As such it was envisaged that the CIEQ will be suitable for use as a stand - alone tool alongside reliable and specific measures of emotions which offers a holistic and intertwined understanding of emergent emotion and its effect to the performance of grade 1 pupils in addition and subtraction. To measure the initial emotion and the subsequent emotion after experiencing colors, the questionnaire employed a Likert Type scale with the following values: 1. Very sad, 2. Sad, 3. Neutral, 4. Happy and 5. Very Happy. 
Originally the choices were limited to sad, neutral and happy but very sad and very happy were added to measure the degree of the changes from negative to positive emotion and vice versa and the changes within the positive or negative emotions. Emoticons were also included in the modified questionnaire to aid the pupils to better identify the emotions. The main questionnaire consisted only of thirteen (13) questions. One question was devoted to the initial emotion and the other twelve were devoted to the resulting emotions after experiencing the specific colors.

Participants were 29 grade 1pupils, male $(n=14)$ and female $(n=15)$, of Philippine Normal University Institute of Teaching and Learning in Manila. Some participants underwent some kindergarten schooling $(\mathrm{n}=24)$ and some did not undergo any form of kindergarten schooling $(\mathrm{n}=$ 5). This cohort of participants represented a wide range of different backgrounds, and experience levels.

The participating teachers were briefed and oriented on the nature of the research and provided with ethical and informed consent details. Since the research subjects were minors the consent of the parents were sought. A written survey comprising two key sections was developed.

The first section recorded participant information regarding age, gender, kindergarten training. Since respondents were grade 1 pupils these information were provided by the teacher based on the class record.

The second section asked participants what they feel at the moment and what they feel whenever they see a particular color using a Likert type scale with the following values: 1. Very sad, 2. Sad, 3. Neutral, 4. Happyand 5. Very happy. Emoticons where also used to visually represent the scale of emotions. To aid the participants in identifying the different colors, the actual color was printed on the questionnaire opposite its name anda visual aid containing the colors and their names were posted in front of the classroom. The teacher was also requested to assist the pupils in recognizing the different colors. No context or examples were provided to participants in order to remove any experimenter bias in responses.

In consideration of the respondents who were only grade 1 pupils, the colors were limited to twelve (12). Initial results were statistically analyzed using the IBM SPSS statistics version 23 to establish the reliability of the instrument. A Cronbach's Alpha of .787 which indicated that these colors were reliable in inducing emotions and which allowed them for inclusion in the questionnaire for the moment. Table 1 below shows the Cronbach's Alpha values if the specific colors were to be deleted.

Table 1: Comparison of the Values of Cronbach's Alpha if a Certain Color were to be Deleted

\begin{tabular}{lcccc} 
& $\begin{array}{c}\text { Scale Mean if } \\
\text { Item Deleted }\end{array}$ & $\begin{array}{c}\text { Scale Variance if } \\
\text { Item Deleted }\end{array}$ & $\begin{array}{c}\text { Corrected Item- } \\
\text { Total Correlation }\end{array}$ & $\begin{array}{c}\text { Cronbach's Alpha } \\
\text { if Item Deleted }\end{array}$ \\
\hline emotion induced by red & 45.83 & 25.868 & .402 & .774 \\
emotion induced by yellow & 45.67 & 24.851 & .519 & .762 \\
emotion induced by blue & 45.77 & 23.426 & .566 & .755 \\
emotion induced by green & 45.70 & 25.459 & .600 & .757 \\
emotion induced by orange & 45.90 & 26.162 & .447 & .770 \\
emotion induced by purple & 45.93 & 27.030 & .268 & .788 \\
emotion induced by brown & 45.93 & 25.513 & .479 & .766
\end{tabular}




\begin{tabular}{lllll} 
emotion induced by grey & 45.97 & 23.964 & .563 & .756 \\
emotion induced by rose & 45.63 & 28.861 & .125 & .796 \\
emotion induced by silver & 46.03 & 25.620 & .480 & .766 \\
emotion induced by gold & 45.40 & 27.697 & .431 & .775 \\
emotion induced by black and & 46.23 & 26.047 & .306 & .787 \\
white & & & \\
\hline
\end{tabular}

The color Grey was retained because its removal would lower the alpha value. Black \& White was retained even though its deletion would not affect the alpha value because many children does not yet know that technically they are not colors and many of their experiences involve black $\&$ white and it was ranked $5^{\text {th }}$ in the initial survey in inducing the positive emotion happy. Purple was retained because its removal would not significantly affect the alpha value yet it has its potential to draw emotions. The researcher decided to wait for the result of the full blown survey before he proceeds limiting the colors to a manageable number for use in the development of learning material in the modules.

Initial survey results showed that when the before and after emotions where correlated only the color red showed significant correlation $(n=29, \mathrm{r}=.570 \mathrm{p}=.001)$ and when subjected to paired sample T-tests only the Black \& White registered a non-significant difference between the before and after emotions $(t=-2.33, s d=1.083, m=-.469, p=.027)$. Red, yellow, blue, green, orange, purple, rose and gold registered a $p$ of $<.001$. Brown and grey registered a significant value of .001 and silver had a $p=.002$.

\section{Stage 2: Validation of the Color Induced Emotion Questionnaire (CIEQ)}

The next process was to design and validate the Color Induced Emotion Questionnaire (CIEQ) using the 12 identified colors from the initial survey.

Participants for this phase were 45 male $(n=25)$ and female $(n=20)$ grade 1 pupils at Ma. Fernando Guerrero Elementary School in Manila. The participants were not part of the initial survey. Data from this group were compared to the data gathered from the PNU group to test the reliability of the questionnaire.

The participants were briefed on the nature and requirements of the project by the researcher and provided them with ethical and informed consent details. Participants whose parents gave consent were asked to individually complete a brief written survey (see Questionnaire on Color). As with the initial survey the first section recorded background information regarding age, gender, kindergarten education as based on their school records. They were assisted by their teachers. The second section presented participants with a matrix where they were asked to indicate what they feel at the moment and whenever they see each of the 12 colors identified in the earlier survey. A Likert Type Scale was used with the following values: 1- very sad; 2- sad; 3-neutral; 4- happy and 5-very happy. Once again, no context or examples were provided to participants in order to remove any leading bias in responses. The colors where printed together with their names in the questionnaire and in the visual aid posted in front of the classroom. Emoticons were also use to correspond to the 5 emotions in the scale.

Participant responses were collated to produce the weighted mean and rank for each color. Results were compared to the result of the first survey. The weighted means of the emotions felt by the respondents was calculated and reported in the table below which serves to 
validate the ability of each color to draw the emotion happy which became the basis for their inclusion in the final questionnaire (CIEQ).

A paired t-test of the weighted means of the emotion felt before and after color was conducted to compare if the emotions before experiencing color was significantly different from the emotion after experiencing colors and then these were compared to the data gathered from the PNU Group. Table 2 below shows that there were no significant differences between the emotions felt before colors by the two groups; $w m=3.44$ for PNU and 3.36 for FMGES. However, there was statistically significant difference in the emotions felt after experiencing colors; $t=-10.623, s d=.193, m=.592, p=<.001$ between the two groups. There werealso statistical significant differences between the emotion felt before and after experiencing colors by the PNU pupils; $t=-8.888 s d=.293, m=-.750, p=<.001$ and that of the FMGES pupils; $t=-$ $319.809, s d=.148, m=-1.70, p=<.001$. These were enough grounds to contend that the subjects felt happier after experiencing color. Thus, some colors may be utilized to induces happy emotion on Filipino grade 1 pupils to improve their learning in math.

Table 2: Paired Sample tests of the emotion before and after experiencing colors by PNU and FMGES pupils

\begin{tabular}{|c|c|c|c|c|c|c|}
\hline & & Mean & $\begin{array}{c}\text { Std. } \\
\text { Deviation }\end{array}$ & $t$ & $d f$ & $\begin{array}{c}\text { Sig. } \\
\text { (2-tailed) }\end{array}$ \\
\hline \multirow[t]{2}{*}{ Pair 2} & PNU wm of emotion after colors vs & & & & & \\
\hline & FMGES wm of emotion after colors & -.592 & .193 & -10.623 & 11 & .000 \\
\hline \multirow[t]{2}{*}{ Pair 3} & PNU wm of emotion before colors vs & & & & & \\
\hline & PNU wm of emotion after colors & -.750 & .293 & -8.888 & 11 & .000 \\
\hline \multirow[t]{2}{*}{ Pair 4} & FMGES wm of emotion before colors & & & & & \\
\hline & vs FMGES wm of emotion after colors & -1.70 & .148 & -39.809 & 11 & .000 \\
\hline
\end{tabular}

When the PNU ITL and FMGES pupils' ranking of colors were compared, there were observed similarities. GOLDand YELLOWwere both found on the first 3 ranks. GOLD slid to $2^{\text {nd }}$ rank for the FMGES but Yellow remained in the $2^{\text {nd }}$ rank. The major differences were; 1 . ROSE which ranked $2^{\text {nd }}$ in the PNU ranking slid to rank 10.5 in the FMGES ranking, 2. BLUE which was ranked $5^{\text {th }}$ by the PNU pupils was ranked $1^{\text {st }}$ by the FMGES pupils, 3 . BLACK \& WHITE which was ranked $11^{\text {th }}$ in the PNU ranking went up to $6^{\text {th }}$ ranked by the FMGES pupils and 4. SILVER which was ranked 10th by PNU ITL pupils, was relegated to rank 12 by the FMGES pupils. ORANGEand GREY had interchanged ranking. GREEN and BROWN somewhat retained their original rankings

As to the ability of these colors to induce the positive emotion happy, the FMGES pupils $(n-45)$ registered more "happy" $(\mathrm{f}=101)$ and "very happy" $(\mathrm{f}=438)$ emotions. There was only 1 
"neutral" emotion induced but no "sad" and "very sad" emotions was registered. An average weighted mean of 4.70 or a verbal interpretation of very happy was obtained.

Results from the PNU ITL pupils $(n=29)$ showed that some colors do not only induced happy emotions but also sad emotions. These explained why the before and after emotion of the PNU group did not register statistically significant difference. The frequency distributions recorded 5 "very sad" emotions, 16 "sad" emotions and 60 "neutral" emotions. However, it also registered 121 "happy" and 146 "very happy" responses. Overall an average weighted mean of 4.11 with a verbal interpretation of "happy" was registered by the group as compared to the initial average weighted mean of 3.36 with a verbal interpretation of "Neutral". So even if there was no significant difference, these colors were able to change the "neutral" emotion to a "happy" one.

Table 3: Comparative Frequency Distributions and Rank of Emotions Felt When the Different Colors were seen by PNU ITL and FMGES Pupils

PNU ITL Pupils

FMGES Pupils

\begin{tabular}{|c|c|c|c|c|c|c|c|c|c|c|c|c|c|c|c|c|c|c|c|}
\hline $\begin{array}{c}\text { Emotio } \\
\text { ns/ } \\
\text { Color }\end{array}$ & $\mathrm{f}$ & $\mathrm{f}$ & 3 & 4 & 5 & $w$ & $w m$ & $\begin{array}{l}V I \\
.\end{array}$ & $R$ & $\begin{array}{c}\text { Emotion } \\
\mathrm{s} / \\
\text { Color }\end{array}$ & 1 & 2 & $\begin{array}{l}3 \\
\mathrm{f}\end{array}$ & 4 & $\begin{array}{l}5 \\
\mathrm{f}\end{array}$ & $w$ & $w m$ & $\begin{array}{l}V \\
I\end{array}$ & $R$ \\
\hline GOLD & 0 & 0 & 0 & 12 & 17 & 133 & $\begin{array}{l}4.5 \\
9\end{array}$ & $\begin{array}{l}\mathrm{V} \\
\mathrm{H}\end{array}$ & 1 & BLUE & 0 & 0 & 0 & 1 & 44 & 224 & $\begin{array}{c}4.8 \\
7\end{array}$ & $\begin{array}{l}\mathrm{V} \\
\mathrm{H}\end{array}$ & 1 \\
\hline ROSE & 0 & 0 & 3 & 12 & 14 & 127 & $\begin{array}{c}4.3 \\
8\end{array}$ & $\mathrm{H}$ & 2 & GOLD & 0 & 0 & 0 & 2 & 43 & 223 & $\begin{array}{c}4.8 \\
4\end{array}$ & $\begin{array}{l}\text { V } \\
\mathrm{H}\end{array}$ & 2.5 \\
\hline $\begin{array}{c}\text { YELLO } \\
\text { W }\end{array}$ & 1 & 0 & 2 & 11 & 15 & 126 & $\begin{array}{c}4.3 \\
4\end{array}$ & $\mathrm{H}$ & 3 & $\begin{array}{c}\text { YELLO } \\
\text { W }\end{array}$ & 0 & 0 & 0 & 2 & 43 & 223 & $\begin{array}{c}4.8 \\
4\end{array}$ & $\begin{array}{l}\mathrm{V} \\
\mathrm{H}\end{array}$ & 2.5 \\
\hline GREEN & 0 & 0 & 4 & 13 & 12 & 124 & $\begin{array}{c}4.2 \\
7\end{array}$ & $\mathrm{H}$ & 4 & RED & 0 & 0 & 0 & 3 & 42 & 222 & $\begin{array}{c}4.8 \\
2\end{array}$ & $\begin{array}{l}\mathrm{V} \\
\mathrm{H}\end{array}$ & 4.5 \\
\hline BLUE & 0 & 3 & 4 & 6 & 16 & 122 & $\begin{array}{c}4.2 \\
1\end{array}$ & $\mathrm{H}$ & 5 & GREEN & 0 & 0 & 0 & 3 & 42 & 222 & $\begin{array}{c}4.8 \\
2\end{array}$ & $\begin{array}{l}\mathrm{V} \\
\mathrm{H}\end{array}$ & 4.5 \\
\hline RED & 0 & 1 & 6 & 10 & 12 & 120 & $\begin{array}{c}4.1 \\
4\end{array}$ & $\mathrm{H}$ & 6 & $\begin{array}{c}\text { BLACK } \\
\& \\
\text { WHITE }\end{array}$ & 0 & 0 & 0 & 7 & 38 & 218 & $\begin{array}{c}4.7 \\
4\end{array}$ & $\begin{array}{l}\mathrm{V} \\
\mathrm{H}\end{array}$ & 6 \\
\hline $\begin{array}{l}\text { ORAN } \\
\text { GE }\end{array}$ & 0 & 1 & 4 & 15 & 9 & 119 & $\begin{array}{c}4.1 \\
0\end{array}$ & $\mathrm{H}$ & 7 & GREY & 0 & 0 & 0 & 8 & 37 & 217 & $\begin{array}{c}4.7 \\
2\end{array}$ & $\begin{array}{l}\text { V } \\
\mathrm{H}\end{array}$ & 7 \\
\hline GREY & 0 & 2 & 7 & 8 & 12 & 117 & $\begin{array}{c}4.0 \\
3\end{array}$ & $\mathrm{H}$ & $\begin{array}{l}8 . \\
5\end{array}$ & $\begin{array}{c}\text { ORANG } \\
\text { E }\end{array}$ & 0 & 0 & 0 & 9 & 36 & 216 & $\begin{array}{c}4.7 \\
0\end{array}$ & $\begin{array}{l}\mathrm{V} \\
\mathrm{H}\end{array}$ & 8 \\
\hline $\begin{array}{c}\text { BROW } \\
\mathrm{N}\end{array}$ & 0 & 0 & 9 & 10 & 10 & 117 & $\begin{array}{c}4.0 \\
3\end{array}$ & $\mathrm{H}$ & $\begin{array}{l}8 . \\
5\end{array}$ & $\begin{array}{c}\text { BROW } \\
\mathrm{N}\end{array}$ & 0 & 0 & 0 & 13 & 32 & 212 & $\begin{array}{c}4.6 \\
1\end{array}$ & $\begin{array}{l}\mathrm{V} \\
\mathrm{H}\end{array}$ & 9 \\
\hline
\end{tabular}




\begin{tabular}{|c|c|c|c|c|c|c|c|c|c|c|c|c|c|c|c|c|c|c|}
\hline $\begin{array}{c}\text { SILVE } \\
\text { R }\end{array}$ & 0 & 1 & 7 & 13 & 8 & 115 & $\begin{array}{c}3.9 \\
6\end{array}$ & $\mathrm{H}$ & 10 & $\begin{array}{c}\text { PURPL } \\
\text { E }\end{array}$ & 0 & 0 & 1 & 18 & 26 & 205 & $\begin{array}{c}4.4 \\
6\end{array}$ & $\mathrm{H}$ \\
\hline $\begin{array}{c}\text { BLAC } \\
\text { K \& } \\
\text { WHITE }\end{array}$ & 0 & 2 & 10 & 8 & 9 & 111 & $\begin{array}{c}3.8 \\
3\end{array}$ & $\mathrm{H}$ & 11 & ROSE & 0 & 0 & 0 & 20 & 25 & 205 & $\begin{array}{c}4.4 \\
6\end{array}$ & $\mathrm{H}$ \\
\hline $\begin{array}{c}\text { PURPL } \\
\text { E }\end{array}$ & 4 & 6 & 4 & 3 & 12 & 100 & $\begin{array}{c}3.4 \\
5\end{array}$ & $\mathrm{~N}$ & 12 & SILVER & 0 & 0 & 0 & 15 & 30 & 210 & $\begin{array}{c}4.5 \\
6\end{array}$ & $\begin{array}{l}\mathrm{V} \\
\mathrm{H}\end{array}$ \\
\hline $\begin{array}{c}\text { Total/av } \\
\text { e } \\
n=29\end{array}$ & 5 & $\begin{array}{l}3 \\
2\end{array}$ & $\begin{array}{c}18 \\
0\end{array}$ & $\begin{array}{c}48 \\
4\end{array}$ & $\begin{array}{c}73 \\
0\end{array}$ & $\begin{array}{c}143 \\
1\end{array}$ & $\begin{array}{c}4.1 \\
1\end{array}$ & $\mathrm{H}$ & & $\begin{array}{l}\text { Total } \\
\mathrm{n}=45\end{array}$ & 0 & 0 & 1 & $\begin{array}{c}10 \\
1\end{array}$ & $\begin{array}{c}43 \\
8\end{array}$ & $\begin{array}{c}2,59 \\
7\end{array}$ & $\begin{array}{c}4.7 \\
0\end{array}$ & $\begin{array}{l}\text { V } \\
\mathrm{H}\end{array}$ \\
\hline
\end{tabular}

These results further showed that the instrument can also measure negative emotions as well as positive emotion which make the questionnaire balanced and unbiased.

\section{FINDING, ANALYSES AND DISCUSSION}

\section{Research question 1: What color induces happy emotion?}

In order to identify what colors induce the emotion happy, two hundred respondents whose class were randomly selected from the grade 1 classes of Philippine Normal University Institute of Learning and Teaching and Ma. Fernando Guerrero Elementary School in Manila, Philippines were asked to accomplish a survey questionnaire on what emotion do they feel whenever they see a particular color using the Likert type scale: 1- very sad; 2-sad; 3-neutral; 4- happy and 5very happy with the corresponding emoticons to facilitate their choices. Since the respondents were grade 1, only simple colors were used such as the primary, secondary and other related colors of which respondents were generally familiar. The other properties and characteristics of colors were not considered in this study since the respondents may not yet be aware of shade, intensity, hue and other properties of colors. The colors where placed beside each question and on the board with their corresponding labels. Grey and Black \& White though not technically colors were also included in the choices since grade 1 pupils were generally familiar with them.

Table 4 shows that over all, the colors presented induced happy emotion $(\mathrm{m}=3.91)$. There were 1,151 responses of "very happy" from which gold got the highest induced "very happy" emotion ( $\mathrm{f}=121)$ followed by red $(\mathrm{f}=118)$ and rose $(\mathrm{f}=12)$, while purple, Black \& White and Grey can also induce "happy" and "very happy" emotions in fewer respondents, even though, they induced the highest negative emotion of "sad" and "very sad". Purple induced "very sad" emotion on 44 respondents, black and white followed with 43 and grey with 25 respondents who felt "very sad" whenever they experience them. The other colors also induced in some respondents the negative emotion of "very sad" and "sad". There were a total of 221 responses of "very sad" (wm=221) and 223 responses of "sad" (wm=446). 
Table 4: Frequency distribution and means of the emotion induced by colors

\begin{tabular}{|c|c|c|c|c|c|c|c|c|c|c|c|c|c|c|}
\hline $\begin{array}{c}\text { Emotions/ } \\
\text { Color }\end{array}$ & $\begin{array}{c}\mathrm{f} \\
\mathrm{Ver} \\
\mathrm{y} \\
\mathrm{sad}\end{array}$ & $\mathrm{W}$ & $\begin{array}{c}\mathrm{f} \\
\mathrm{Sad}\end{array}$ & $\mathrm{w}$ & $\begin{array}{c}\mathrm{f} \\
\text { Neutra } \\
1\end{array}$ & $\mathrm{~W}$ & $\begin{array}{c}\mathrm{f} \\
\text { Happ } \\
\mathrm{y}\end{array}$ & $\mathrm{W}$ & $\begin{array}{c}\mathrm{f} \\
\text { Very } \\
\text { happ } \\
\mathrm{y}\end{array}$ & $\mathrm{w}$ & $\begin{array}{c}\text { Total } \\
\text { w }\end{array}$ & WM & V.I & Rank \\
\hline RED & 15 & 15 & 26 & 52 & 8 & 24 & 33 & 132 & 118 & 590 & 813 & 4.07 & $\mathrm{H}$ & 4 \\
\hline $\begin{array}{l}\text { YELLO } \\
\mathrm{W}\end{array}$ & 10 & 10 & 12 & 24 & 10 & 30 & 63 & 252 & 105 & 525 & 841 & 4.21 & $\mathrm{H}$ & 2 \\
\hline BLUE & 13 & 13 & 15 & 30 & 33 & 99 & 37 & 148 & 102 & 510 & 800 & 4.00 & $\mathrm{H}$ & 7 \\
\hline GREEN & 12 & 12 & 16 & 32 & 30 & 90 & 33 & 132 & 109 & 545 & 811 & 4.06 & $\mathrm{H}$ & 5 \\
\hline ORANGE & 9 & 9 & 17 & 34 & 27 & 81 & 58 & 232 & 89 & 445 & 801 & 4.01 & $\mathrm{H}$ & 6 \\
\hline PURPLE & 44 & 44 & 21 & 42 & 10 & 30 & 42 & 168 & 83 & 415 & 699 & 3.50 & $\mathrm{~N}$ & 11 \\
\hline BROWN & 18 & 18 & 16 & 32 & 28 & 84 & 55 & 220 & 83 & 415 & 769 & 3.85 & $\mathrm{H}$ & 8 \\
\hline GREY & 25 & 25 & 20 & 40 & 39 & 117 & 40 & 160 & 76 & 380 & 722 & 3.61 & $\mathrm{H}$ & 10 \\
\hline ROSE & 7 & 7 & 16 & 32 & 19 & 57 & 46 & 184 & 112 & 560 & 840 & 4.20 & $\mathrm{H}$ & 3 \\
\hline SILVER & 16 & 16 & 23 & 46 & 29 & 87 & 57 & 228 & 75 & 375 & 752 & 3.76 & $\mathrm{H}$ & 9 \\
\hline GOLD & 9 & 9 & 8 & 16 & 17 & 51 & 45 & 180 & 121 & 605 & 861 & 4.31 & $\mathrm{H}$ & 1 \\
\hline $\begin{array}{l}\text { BLACK } \\
\text { AND } \\
\text { WHITE }\end{array}$ & 43 & 43 & 33 & 66 & 15 & 45 & 28 & 112 & 78 & 390 & 656 & 3.33 & $\mathrm{~N}$ & 12 \\
\hline Total & 221 & $\begin{array}{c}22 \\
1\end{array}$ & 223 & 446 & 265 & 795 & 537 & 2148 & 1151 & 5755 & 9365 & 3.91 & $\mathrm{H}$ & \\
\hline
\end{tabular}

Legend: $f=$ frequency

verbal

interpretation

When ranked according to the weighted mean, Gold came first $(\mathrm{wm}=4.31)$, followed second by Yellow $(\mathrm{wm}=4.21)$ and third by Rose $(\mathrm{wm}=4.20)$. The lowest ranked colors were Black and White $(\mathrm{wm}=3.33)$, Purple $(\mathrm{wm}=3.50)$ and Grey $(\mathrm{wm}=3.61)$ respectively.

The first five ranked Colors namely; Gold, Yellow, Rose, Red and Green were used in the materials of addition modules to enrich the performance of the pupils.

The results of the survey on colors showed that some colors induced positive emotions like happy, some induced negative emotions and some induced both positive and negative emotions yet others do not induce emotion and remained neutral. The colors Gold, Yellow, Rose, Red, Green and Orange were considered happy color inducers by the subject pupils. This is based on the ranking of colors according to their weighted mean. Gold ranked first, followed second by Yellow and third by Rose. The lowest ranked colors were Black \& White, Purple and Grey respectively. These were consistent with color psychology that posited that Yellow is the color of happiness and sunshine for children. Yellow is supposed to stimulate intelligence and is ideal for use in kids' rooms, study rooms and play areas. Red is said to be the color of passion and strong feelings of threat, love, or excess stimulus. In school rooms, it can be used in combination with other colors as it can help in detail oriented or repetitive tasks. Rose is believed to be a calming color and is believe to lower heart rate. Green is considered as the color of abundance which can relax and contribute to better health in kids and Orange is used by many educational institutes to enhance critical thinking and memory.

According to Mariam and Muhammad (2013) colors are believed to be the most important visual experience of human beings. It functions as a powerful information channel to the human cognitive system and has been found to play a significant role in enhancing memory performance. They further claimed that colors can play a positive role in affecting learners' 
cognitive retention (Mariam and Muhammad, 2013) and that they are powerful elements that produce profound psychological and physiological reactions. Mariam and Muhammad (2013) further found that there was a significant relationship between color preferences, emotions, and academic performance in students which is in agreement with the findings of Gaines and Curry (2011).

The findings of this study on colors also showed that the males registered the highest difference in the change toward positive emotion in color rose while the female gave the highest mean difference to Gold. The males gave the highest difference towards negative change in emotion to black \& white while the females gave it to color purple. The lowest change towards positive emotion was given by the males to the color orange while the lowest change towards negative emotion was given by the females to Grey. However, these differences in the effects of colors to the male and female pupils when subjected to t-test at .005 significance level showed that there was no significant difference between the antecedent emotion and the consequent emotion of the males and females and that the effects of these colors to the consequent emotions of both male and female were not statistically significant. So even though the color preferences expressed by the children seem to reflect the pattern of color stereotypes held in the adult culture wherein the majority of girls chose either pink or purple and the majority of boys choose either blue or red which is consistent with the findings of Paoletti (2012), the findings of this study did not find any significant difference in the antecedent and consequent emotions based on the color preference of males and females. This may be because the young pupils had not yet been strongly affected by stereotypes like adults do.

Lastly, the findings of this study on the ability of colors to induce happy emotion should be generalized only and should be limited to the use of simple colors. Aside from this, the current study had to contend with some limitations in studying the ability of colors to induce happy emotion. One problem is the tendency to describe the effect of colors holistically or categorically even though this study only used generic colors. The effects of colors are actually due to the contrasts of three relative attributes that define all colors: first the value, (light vs. dark, or white vs. black) second, the chroma, (saturation, purity, strength, intensity) and third the Hue (the name of the color family: red, yellow, green, cyan, blue and magenta). Since the respondents of this study were young children, only the hue was considered because these pupils may not yet have a working knowledge of the chroma and the value of colors. The results may have been different if these two were added to this study. So, the generalization of the findings of this study is limited and not universal. However, since the simple colors were found to induce happy emotion this may still be of benefit even though limited and may be of help in improving the performance of pupils and may serve as a starting point to a more comprehensive study that would involve the effect of chroma and value.

\section{Is there any significant difference on the performance in Addition of the Control and the experimental groups?}

Table 5, presents the Pre and Post test Scores of the Control Group and the experimental Group. When compared, the Experimental group (Color group) have higher addition scores $(\mathrm{sum}=534)$ than the Control group (sum=500). Comparison of the pretest and the post-test showed an increase in the scores from 500 to 574 in the control group. While the Color group registered an increased scores of from 534 to 771 . 
The total mean of the pretest of the control group (7.04) increased in the post test (8.08). Similarly, the pretest mean of the color group also increased from 7.00 in the pretest to 9.52 in the post test. The mean grade in math of both groups for the $1^{\text {st }}$ grading to second grading period also registered an increase from 82.44 to 83.73 for the control group and from 80.56 to 83.20 for the color group.

Table 5: Sum of Pre-test, Post test Scores and of the $1^{\text {st }}$ and $2^{\text {nd }}$ Grading Grades of the Control group and the Color Group

\begin{tabular}{|c|c|c|c|c|c|c|}
\hline \multirow[t]{2}{*}{ Groups } & \multicolumn{2}{|c|}{ Pre-Test Scores } & \multicolumn{2}{|c|}{ Post - Test Scores } & \multicolumn{2}{|c|}{$\begin{array}{c}\text { Mean Grade Per Grading } \\
\text { Period }\end{array}$} \\
\hline & Sum & Mean & Sum & Mean & $1 \mathrm{st}$ & 2nd \\
\hline Control & 500 & 7.04 & 574 & 8.08 & 82.44 & 83.73 \\
\hline Color & 534 & 7.00 & 771 & 9.52 & 80.56 & 83.20 \\
\hline
\end{tabular}

The paired t-test, (see table 6 below), registered a statistically significant improvements in the performance of the color group. It also registered a significant improvement compared to the control group $(\mathrm{t}(70)=-10.29, \mathrm{~m}=-1.93, \mathrm{sd}=1.5, \mathrm{p}=<.001)$ and the subjects' grade $(\mathrm{t}(70)=-$ $6.820, \mathrm{~m}=-1.803, \mathrm{sd}=-1.803, \mathrm{p}=<.001)$.

Though there were improvements in the performance of the control group $(\mathrm{t}(70)=-7.04$, $\mathrm{m}=-1.04, \mathrm{sd}=1.23, \mathrm{p}=<.001)$, and their grades $(\mathrm{t}(40)=-8.67, \mathrm{~m}=-1.29, \mathrm{sd}=.96, \mathrm{p}=<.001)$ which were all statistically significant, they cannot eclipse the better performance of the Color group which registered significant gains $(\mathrm{t}(80)=-26.75, \mathrm{~m}=-.292, \mathrm{sd}=.99, \mathrm{p}=<.001)$, and their Grades $(\mathrm{t}(80)=-11.17, \mathrm{~m}=-2.64, \mathrm{sd}=2.13, \mathrm{p}=<.001)$.

Thus, it appears that the claim that happy emotion induced by colors improves the addition performance of the subject pupils may have statistical basis.

Table 6: Paired T-Test Results of the Pre and Post Test Scores of the Control group vs the Color group

\begin{tabular}{lccccc}
\hline Control Group & mean & $\mathrm{sd}$ & $\mathrm{t}$ & $\mathrm{df}$ & $\begin{array}{c}\text { Sig } \\
(2 \text { tailed })\end{array}$ \\
\hline $\begin{array}{l}\text { Addition Pre-post } \\
\text { test }\end{array}$ & -1.04 & 1.23 & -7.04 & 70 & .000 \\
$\begin{array}{l}\text { Grades } \\
\text { Color Group }\end{array}$ & -1.29 & .96 & -8.67 & 40 & .000 \\
$\begin{array}{l}\text { Addition Pre-post } \\
\text { test }\end{array}$ & -.292 & .99 & -26.75 & 80 & .000 \\
$\begin{array}{l}\text { Grades } \\
\text { Control VS Color group }\end{array}$ & -2.64 & 2.13 & -11.17 & 80 & .000 \\
$\begin{array}{l}\text { Addition } \\
\text { Grade }\end{array}$ & -1.930 & 1.580 & -10.293 & 70 & .000 \\
\hline
\end{tabular}

The finding that colors improve performance may be understood in the context that colors were found to be the most important visual experience of human beings (Mariam and Faiz, 2013). Colors function as powerful information channel to the human cognitive system and have been found to play significant role in enhancing memory performance. In searching for strategies to 
improve the performance of pupils in addition, it appeared, based on the initial survey results, that colors are capable of inducing the positive emotion happy and of motivating students to learn and to profit from their educational experiences as suggested by Wichmann, Sharpe, and Gegenfurtner (2002). In addition, this finding was also congruent with other studies which established that colors influence the way we see and process information and improve our ability to remember both words and pictures, (Myers, 2005) that students performed better in recognizing the color of items than shapes (Pan, 2010) and that colors can play a positive role in affecting learners' cognitive retention (Mariam and Faiz, 2013)

\section{CONCLUSION}

Based from the findings of this study, the following conclusions were induced:

1. There are colors that can actually induces happy emotion which may be utilized in the emotion-based teaching aids.

2. Happy emotion induced by some colors can and were found to improve the performance of grade 1 Filipino pupils in addition and subtraction.

3. Teaching aids which utilized the principles, characteristics and strengths of emotionbased teaching are promising alternatives to other cognitive-based strategies in improving children's performance in math.

\section{RECOMMENDATIONS}

This study recommends to policy makers to formulate guidelines in the effective utilization of emotion-based teaching inside and outside the classrooms so that the use of emotion-based teaching and learning will become institutionalized.

The study further recommends that math teachers especially in early childhood education to take cognizance of these findings and be emboldened in the use of emotion-based teaching so that their pupils will benefit from it by performing better not only in math but in life since it was commonly accepted that early childhood education affects future performance. Teachers are encouraged to create better classroom learning environment by using colors to induce happy learning atmosphere and to make their pupils happy so that instead of unconsciously developing math anxiety, they may instead develop at the early stage a love for mathematics. Aside from this, the text books, learning materials and teaching aids in math should also be developed utilizing the principles of emotion-based teaching and the power of emotions in effecting better learning. Furthermore, school management should encourage teachers to use emotion-based teaching by tapping the benefits of positive emotions in mathematics to develop emotive learning skills- the skill to use emotion towards better learning.

The study also recommends that the Philosophy of Education of the Philippines, the Department of Education's Mission/Vision and the school organizations' goals and directions should be reviewed and set clearly to achieve competence, excellence and global competitiveness through both mental and emotional developments utilizing the potent role of emotions in the teaching-learning process to make education more human, humane and holistic. 
Lastly, further study is recommended using related or other variables and inducers to induce different positive emotions in an attempt to improve the performance of Filipino children on the four basic mathematical skills and other foundation skills.

\section{REFERENCES}

Al-Ayash, A., Kane, R. T., Smith, D., \& Green-Armytage, P. (2016). The influence of color on student emotion, heart rate, and performance in learning environments. Color Research \& Application, 41(2), 196-205.

Arguedas, M., Daradoumis, A., \& Xhafa, F. (2016). Analyzing how emotion awareness influences students' motivation, engagement, self-regulation and learning outcome. Educational Technology and Society, 19(2), 87-103.

Blair, J., Czaja, R. F., \& Blair, E. A. (2013). Designing surveys: A guide to decisions and procedures. Thousand Oaks, CA: Sage Publications.

Department of Education. (2015). K-12 Basic education curriculum. Retrieved July 2, 2018 from http://www.deped.gov.ph/k-to-12/about/k-to-12-basic-education-curriculum/

Gaines, K. S., \& Curry, Z. D. (2011). The Inclusive Classroom: The Effects of Color on Learning and Behavior. Journal of Family \& Consumer Sciences Education, 29(1).

Heidig, S., Müller, J., \& Reichelt, M. (2015). Emotional design in multimedia learning: Differentiation on relevant design features and their effects on emotions and learning. Computers in Human Behavior, 44, 81-95.

Izard, C. E. (2009). Emotion theory and research: Highlights, unanswered questions, and emerging issues. Annual Review of Psychology, 60, 1-25.

Jocano, F. L. (2000). Work values of successful Filipinos. Quezon City, Philippines: PUNLAD Research House.

Lerner, J. S., Li, Y., Valdesolo, P., \& Kassam, K. S. (2015). Emotion and decision making. Annual Review of Psychology, 66, 799-823.

Mariam Adawiah, D., \& Muhammad Faiz, M. (2013). The influence of colour on memory performance: A review. The Malaysian Journal of Medical Sciences: MJMS, 20(2), 3.

Mayer, R. E., \& Estrella, G. (2014). Benefits of emotional design in multimedia instruction. Learning and Instruction, 33, 12-18.

Myers, R. G. (2005). In search of quality in programmes of early childhood care and education (ECCE). A paper prepared for the.

Pan, Y. (2010). Attentional capture by working memory contents. Canadian Journal of Experimental Psychology/Revue Canadienne de Psychologie Expérimentale, 64(2), 124.

Paoletti, J. B. (2012). Pink and blue: Telling the boys from the girls in America.Indiana, IN: Indiana University Press.

Park, B., Knörzer, L., Plass, J. L., \& Brünken, R. (2015). Emotional design and positive emotions in multimedia learning: An eyetracking study on the use of anthropomorphisms. Computers \& Education, 86, 30-42.

Pekrun, R. (2006). The control-value theory of achievement emotions: Assumptions, corollaries, and implications for educational research and practice. Educational Psychology Review, 18(4), 315-341.

Pekrun, R., \& Linnenbrink-Garcia, L. (2014). Introduction to emotions in education. In International handbook of emotions in education (pp. 11-20). England, UK: Routledge.

Plass, J. L., Heidig, S., Hayward, E. O., Homer, B. D., \& Um, E. (2014). Emotional design in multimedia learning: Effects of shape and color on affect and learning. Learning and Instruction, 29, 128-140.

Plass, J. L., Heidig, S., Hayward, E. O., Homer, B. D., \& Um, E. (2014). Emotional design in multimedia learning: Effects of shape and color on affect and learning. Learning and Instruction, 29, 128-140.

Plass, J. L., Homer, B. D., \& Hayward, E. O. (2009). Design factors for educationally effective animations and simulations. Journal of Computing in Higher Education, 21(1), 31-61.

Russell, J. A. (2003). Core affect and the psychological construction of emotion. Psychological Review, $110(1), 145$.

Singh, M., Singh, M. M., \& Singhal, N. (2013). Ann based emotion recognition. Emotion, 1, 56-60.

Suk, H. J., \& Irtel, H. (2010). Emotional response to color across media. Color Research \& Application: Endorsed by Inter-Society Color Council, The Colour Group (Great Britain), Canadian Society for Color, Color Science Association of Japan, Dutch Society for the Study of Color, The Swedish Colour Centre Foundation, Colour Society of Australia, Centre Français de la Couleur, 35(1), 64-77. 
Sutton, T. M., \& Altarriba, J. (2016). Color associations to emotion and emotion-laden words: A collection of norms for stimulus construction and selection. Behavior Research Methods, 48(2), 686-728.

Tendler, A., \& Wagner, S. (2015). Different types of theta rhythmicity are induced by social and fearful stimuli in a network associated with social memory. ELife, 4. doi:10.7554/eLife.03614

Tyng, C. M., Amin, H. U., Saad, M. N., \& Malik, A. S. (2017). The influences of emotion on learning and memory. Frontiers in Psychology, 8, 1454.

Vail, P. (2016). The role of emotions in learning. Retrieved February 17, 2017, http://www.greatschools.org/gk/author/priscillalvailmat/

Wichmann, F. A., Sharpe, L. T., \& Gegenfurtner, K. R. (2002). The contributions of color to recognition memory for natural scenes. Journal of Experimental Psychology: Learning, Memory, and Cognition, 28(3), 509.

Wilms, L., \& Oberfeld, D. (2018). Color and emotion: effects of hue, saturation, and brightness. Psychological Research, 82(5), 896-914.

Wolfe, P. (2006). The role of meaning and emotion in learning. The Neuroscience of Adult Learning: New Directions for Adult and Continuing Education, Number 110, 81, 35. 